\title{
La maestra española de la tradición a la modernidad
}

\author{
Sonsoles San Román Gago*
}

\begin{abstract}
RESUMEN: El objetivo de este trabajo es explicar el origen y desarrollo de la incorporación de la maestra a la escuela pública en España desde 1783 a 1882. En la línea temporal que cruza este período histórico, de la llustración a la Restauración, he creído encontrar fundamentos teóricos, educativos, sociales, políticos, religiosos y económicos suficientes para trazar una tipología de maestras que permite mostrar sus fases de incorporación a la escuela pública. Estos períodos reflejan, por otro lado, un tipo de discriminación tanto negativa, vía exclusión maestra analfabeta -, como positiva, vía inclusión - maestra maternal y racional intuitiva. El estudio se encuadra dentro de una investigación realizada en España, defendida como tesis doctoral en el año 1996 con el título Las transformaciones sociales de la profesión de maestra en España, 1772-1882, y, posteriormente revisada en el Instituto de Educación de la Universidad de Londres. Las conclusiones de esta investigación han sido recientemente publicadas con el título: Las primeras maestras. Los orígenes del proceso de feminización docente en España. ${ }^{1}$
\end{abstract}

Plabras llave: Maestra, escuela pública, proceso de feminización, Espanã

\section{La maestra analfabeta (1783-1838)}

Las primeras maestras que desarrollan su actividad en las escuelas públicas de niñas carecían de las bases mínimas de alfabetización, pues no sabían leer ni escribir. Y, sin embargo, en el contexto social y cultural donde ejercían el oficio de enseñar, su exclusión educativa era congruente con

Docente da Universidade Autônoma de Madri. E-mail: s.sanroman@uam.es 
el ideal de cultura femenina defendido en el ámbito privado y público, es decir, por la familia y el Estado. Efectivamente, la educación femenina se encontraba circunscrita al espacio doméstico; círculo privado del hogar donde debía desarrollar su actividad. A la maestra analfabeta (primer modelo de maestra de escuela pública, que supone la primera fase de incorporación de la maestra a la escuela pública de niñas, y se produce vía exclusión de la educación de los niños) se le encomendó la tarea de reproducir ese ideal de cultura femenina que aseguraba la educación hogareña de las niñas de las clases más desfavorecidas.

Es cierto que los presupuestos eran escasos, pero la exclusión femenina no se produjo tanto por un problema económico, cuanto social, cultural y religioso. Quedaba aquí abandonada a la suerte del destino esa masa remanente de sujetos dominados, entre ellos las mujeres, a quienes no iba dirigido el mensaje de igualdad y libertad proclamado por los ilustrados. ${ }^{2} \mathrm{Y}$, precisamente, dentro de esta categoría residual, la maestra, por su condición de mujer, quedaba excluida de libertad y privada del derecho a recibir cultura e instrucción. Otros agentes sociales con capacidad para decidir sobre su educación escogieron los modelos educativos femeninos más acordes a sus particulares intereses políticos, económicos, morales y sociales. ${ }^{3}$

\section{Presupuestos teóricos}

¿Qué presupuestos teóricos manejaron nuestros ilustrados para negar a la mujer el derecho de instrucción? ¿Qué planteamientos dieron luz verde a la implantación del modelo de maestra analfabeta? Para responder a esta pregunta analizaré la opinión de Rousseau y Kant, a quienes considero representantes de la mentalidad de la época. ${ }^{4}$

Mi propósito es ahora señalar esas páginas que con tanta frecuencia han sido olvidadas por nuestros investigadores sociales. Veamos cuales son las posturas de Rousseau y Kant. Concuerdan entre ellos en que el estado natural de la mujer es el de dependencia, pues opinan que la natural debilidad que supone la maternidad le lleva a necesitar un hombre a su lado para que la proteja, la cuide y produzca los bienes materiales necesarios para llevar el hogar, porque "la economía del varón consiste en ganar, (y) la de la mujer, en ahorrar" (Kant 1990, p. 259).

Por supuesto que estos hombres eran conscientes del estado de desigualdad en que se hallaba la mujer, pero el caso es que este hecho no se consideraba un problema social (Rousseau 1973). ${ }^{5}$ La imposibilidad natural 
asignada por su condición femenina a la maestra analfabeta la excluye del derecho a participar en la educación de los niños, que no de las niñas, y por tanto del derecho a recibir los rudimentos de la alfabetización. Las diferencias entre hombres y mujeres están determinadas en su opinión por cualidades naturales y/o sobrenaturales que determinan para estas últimas su destino: el hogar y el matrimonio.

El destino de la mujer es uno, el mismo para todo el sexo femenino: la maternidad y el matrimonio. Y para llevar a buen fin este cometido la naturaleza ha tenido a bien dotarla de ciertas características femeninas - la dulzura, la paciencia, la limpieza y el pudor - que de momento son suficientes para educar a sus retoños. La exaltación de estas cualidades femeninas terminará por dar lugar a altas tasas de participación femenina en la escuela, espacio público que requiere la presencia de una maestra para cuidar de hijos ajenos. ${ }^{6}$

Rousseau y Kant afirman que la mujer carece de autonomía, que está incapacitada, castrada por naturaleza. Su estado natural solo puede ser uno, el de dependencia. Su condición de insuperable inferioridad la convierte en sujeto dependiente, sin otro remedio que obedecer al hombre. Incapacitada para deducir la regla de sus acciones a partir de sí misma, sin principio estable, sin carácter, como apunta Kant, su filosofía no consiste en entender, sino en sentir. De esta manera su ámbito de acción queda reducido al terreno de lo práctico. Así, el carácter sensible, que no intelectual, del sexo femenino determina el criterio por el cual debe guiarse la educación de la mujer.

Justificada su exclusión, la mujer queda eliminada del derecho de ciudadanía. ${ }^{7}$ ¿Para qué les iba a servir a estas primeras maestras de escuela publica saber leer o escribir? La única educación que debían recibir las mujeres, siguiendo la opinión de estos autores, era la que sus madres les pudieran proporcionar. Efectivamente, tanto Rousseau como Kant otorgan a la mujer el papel de maestras de la infancia para el varón, y de sus hijas durante toda la vida: "del esmero de las mujeres depende la primera educación de los hombres. Educarlos cuando niños, cuidarlos cuando sean mayores" (Rousseau 1973, pp.248-250). Por ley natural, las mujeres, tanto por sí mismas como por sus hijos, están a merced de los hombres - "cada uno debe disciplinar a su sexo". Se hace bien confiando a las madres la educación de sus hijas y "eximiendo a éstas de los libros" porque la cultura "debilita (...) los encantos mediante los cuales ejercen ellas su gran poder sobre el otro sexo". En la mujer "todos los primores deben agruparse únicamente para realzar el carácter de lo bello", pues "le resultan insoportables todos los mandatos y todas las presiones 
bruscas. Ellas lo hacen todo únicamente porque así les agrada" (Kant 1990 p. 105). El paso desde este estado de naturaleza al de civilización choca con la resistencia natural de la mujer para acatar los mandatos propios de la disciplina.

Ahora nos encontramos en condiciones de comprender los motivos por los cuales Rousseau no consideró aconsejable separar a Sophie de su familia. ¡Fuera nodrizas, hayas, y demás personal doméstico empleado para sustituir la figura de la madre! Según él, sólo si la mujer era educada en el hogar por su madre se podía asegurar una futura voluntad firme para educar a sus propios hijos. El problema era que esas madres eran analfabetas y sólo podían transmitir a sus hijas comportamientos específicamente femeninos y domésticos - pero no instrucción - que reproducían en las pequeñas esa imprescindible cultura femenina tan apropiada para asegurar los lazos de dependencia. ${ }^{8}$

En la misma línea de Kant, Rousseau juzga que los estudios de la mujer no deben ser teóricos. En su formación tendrían que conformarse con aplicar los principios hallados por el hombre - Kant llegará a afirmar que la mujer, por su función social de dependencia, "debe conocer más a los hombres que a los libros". Las madres deben intervenir sirviendo de ejemplo para que sus hijas desarrollen sus disposiciones naturales, su comportamiento ha de ser irreprochable. De esta manera, cada generación trasmitirá a la otra sus conocimientos y experiencias" (Kant 1990, p. 105 y p. 34) con lo cual el estado de analfabetismo queda asegurado.

\section{La maestra analfabeta en la legislación}

Para comprender este primer modelo de maestra que aparece en España, maestra analfabeta, es preciso retroceder hasta finales del siglo XVIII, período en el que Carlos III (1716-1788) sentó las bases de esos primeros proyectos de instrucción pública con los que se inicia la andadura profesional de la maestra española. El 14 de agosto de 1768 aparecen las normas para el establecimiento de casas destinadas a la educación de niños y niñas. El rey considera conveniente que la educación de la juventud no se limite sólo a los varones; las niñas tienen que ir a la escuela pública, espacio donde se empaparán del aroma de esa moral y costumbres que impregnará sus hogares. El monarca ordena que en aquellos pueblos en que las autoridades consideren oportuno se establezcan casas de enseñanza para niñas, recomendando que estos centros se dediquen exclusivamente a la educación del sexo femenino, y prohibiendo expresamente que se junten ambos sexos (la coeducación había sido prohibida por el legislador en la Real Provisión de 20 de diciembre de 1743, la Real 
Provisión de 11 de julio de 1771 y la Real Provisión de 22 de diciembre de 1780). El monarca especifica que las personas encargadas de la educación de las niñas serían "matronas honestas" e instruidas, idóneas para cuidar de su formación y cultivar en ellas los principios y obligaciones de la vida civil y cristiana y las habilidades propias de su sexo. El plan de estudios que propone incluía tales principios, obligaciones y habilidades.

En 1771, Carlos III establecerá los requisitos necesarios para el magisterio de Primeras Letras. Las condiciones que se exigen para ejercer varían en función del sexo. Para ser maestro era necesario pasar una prueba de doctrina cristiana, mostrar la peripecia en el arte de leer y escribir, saber contar, demostrar buena vida y costumbres y entregar un certificado de limpieza de sangre. La maestra, sin embargo, sólo necesitaba un informe acerca de su vida y costumbres, y ser examinada de doctrina cristiana "por la persona que dispute el ordinario, y Licencia de la justicia, oído el síndico y personero sobre las diligencias previas"(Martínez Alcubilla 1880, pp.1517-1518). Es decir, que a las maestras con escuela abierta tan sólo se les pedía ser portadoras de buena reputación, fama y costumbres, junto con algún que otro conocimiento de la doctrina cristiana, por lo demás podían ser analfabetas; su formación debía ser moral, no intelectual. El camino de la maestra hasta conseguir la igualdad formal estará sembrado de obstáculos, que serán difíciles de vencer por unas mujeres acostumbradas a ver la desigualdad social como un hecho natural (Subirats 1990, pp.209-228).

¿Debían las maestras pasar algún tipo de prueba o examen? En caso afirmativo: ¿quién las examinaba?, ¿cuál era el curriculum que se las exigía? Por el Auto Acordado de 30 de marzo de 1778 se crean las Diputaciones de Barrio de Madrid, formadas por el Alcalde de Barrio, un eclesiástico nombrado por el párroco respectivo, y tres vecinos acomodados y celosos, elegidos dentro del propio barrio, que no cobraban por su trabajo, con lo que asumían el planteamiento de apoyo social. El rey ordena que las diputaciones examinen a las maestras de su "habilidad, suficiencia, buen porte, conducta y capacidad para gobernar con acierto" su escuela. Las candidatas tenían que presentar a las diputaciones un memorial informando de su habilidad y costumbres, después estos centros sometían a las maestras a una prueba de habilidad para asegurarse de que sabían coser y conocían el catecismo. Con todo, esta prueba no ofrecía al monarca la suficiente garantía para proceder sin más a la elección de la maestra, por lo que decide delegar en las diputaciones, que debían acertar con las más dignas: "Se preferirá siempre a las de mejores costumbres en concurso de igual habilidad". El control sigue escalonándose. El monarca considera oportuno imponer un reglamento para que las maestras 
cumplan con sus obligaciones; de hecho, los individuos de las diputaciones vigilaban su trabajo y las auxiliaban si era necesario.

La Real Cédula de 11 de mayo de 1783, fecha en que se establecían oficialmente las escuelas de niñas en el país, supuso el primer reconocimiento legal de la necesidad de alfabetizar a las mujeres (art. 11); exigencia sin precedentes en la historia de nuestro país. El monarca era muy consciente de la relevancia que podía adquirir alfabetizar a la mujer para lograr la uniformización de la cultura a escala nacional y propiciar el desarrollo económico; preocupación básica en un momento en el que se asistía al arranque industrial en algunas zonas de Europa. A tenor de esta Real Cédula, que contempla la posibilidad de alfabetizar a la mujer, es posible considerar un error seguir utilizando el termino maestra analfabeta. A este respecto debemos tener en cuenta no sólo que en el momento de promulgarse la ley la maestra seguía en total desconocimiento de los principios de la lectura, sino que, además, esta era una exigencia teórica que no se cumplía en la totalidad de los casos.

El Informe Quintana de 1812, que aborda importantísimas cuestiones relativas a la escolarización masculina, no se plantea como problema público, político o social el asunto de la formación de la maestra, ni, consiguientemente, el tema de la instrucción de las niñas. De la educación de la mujer, para quien se considera más conveniente que reciba una formación de carácter moral que instructiva, nada se dice, al entender que su trabajo, función y misión se encuentran circunscritos y limitados al ámbito familiar y doméstico, pero no al laboral: "La Junta entiende que al contrario que la instrucción de los hombres, que conviene que sea pública, la de las mujeres debe ser privada y doméstica, que su enseñanza tiene más relaciones con la educación que con la instrucción propiamente dicha" (Quintana 1946, pp. 176-177).

Las declaraciones del Informe tendrán una clara repercusión en el Proyecto de Decreto para el Arreglo General de la Enseñanza Pública de 1814, que dedicó todo su titulo XII a la educación de las mujeres, insistiendo en educarlas para cumplir con su destino de madre de familia. En el citado proyecto el legislador se limitó a recomendar, que no a obligar, la creación de escuelas públicas femeninas, donde las niñas aprenderían a leer y a escribir, mientras que las adultas, demasiado mayores para aprender estos conocimientos mínimos, se tendrían que conformar con cultivarse en las labores y habilidades propias de su sexo (art. 115). El gobierno encargaría a las diputaciones provinciales que propusieran el número de escuelas que debían establecerse en sus respectivas provincias, los parajes en donde debían situarse, su dotación y arreglo (art. 116). 
El gobierno confía a las diputaciones y autoridades locales el establecimiento de centros educativos para la mujer (los profesores y profesoras, que dependían económicamente de las diputaciones, quedaban a la libre disposición de estos organismos; de hecho, sus sueldos oscilaban en función del censo de población y la riqueza de los municipios para los que trabajaban). Como resultado de esta confianza que el Gobierno depositó en los ayuntamientos (recuérdese que delegaba en ellos la decisión de abrir escuelas para niñas), se produjo una situación caótica, y parece que todo quedó a merced de la libre voluntad de los intereses detentados por tales organismos. Así, los representantes de la autoridad, en función de sus posibilidades, demandas e intereses particulares tenían "total libertad" para abrir los establecimientos de educación femenina que considerasen oportunos.

El 24 de marzo de 1814, liberado por los franceses, llega al poder Fernando VII (1814-1833), Ilamado el Deseado..$^{9}$ El Decreto de 19 de noviembre de 1815 muestra el retroceso que sufre, de manera especial, la enseñanza primaria. El monarca, que mantenía un concepto de caridad muy diferente al de Carlos III, hace un llamamiento, que más bien puede considerarse una orden, a los conventos de órdenes religiosas, con el fin de resolver el problema económico de su Real Erario y satisfacer esta necesidad que se estaba creando "en justa correspondencia a las limosnas y bienes que han salido y salen de los pueblos donde están fundados; en debida observancia de la obligación de propagar el conocimiento de la religión y la enmienda de las costumbres en gran manera relajadas por la pasada irrupción francesa, y en demostración también de su gratitud a los bienes que con larga mano les ha dispensado mi paternal y religioso desvelo (...) dispondréis lo conveniente al cumplimiento de este mi Real Decreto, a fin de que a la menor brevedad se emprenda una obra que a la vez reclaman la Religión y el Estado". Más adelante, en otro Real Decreto de 18 de julio de 1816, se llegaría incluso a solicitar el establecimiento de escuelas de niñas en los conventos femeninos.

El primer gobierno del Trienio Constitucional (1821-23) se nutrió de exiliados y liberales que acababan de ser liberados de las prisiones. Se produce así el nacimiento del primer texto legal que dará lugar a una nueva estructura de carácter liberal: el Reglamento General de Instrucción Pública de 1821, en el cual pueden apreciarse los primeros trazos que perfilan, tímidamente, ese curriculum orientado a educar a la mujer para el cumplimiento de su papel como madre de familia. Por vez primera el legislador se preocupaba por enseñar a las niñas en las escuelas no sólo a leer y escribir, sino también a contar (art. 120) -S asignatura muy útil para hacer la compra - que llegaría a la Ley Moyano con el nombre de economía doméstica. Aunque en teoría parece 
que nos encontramos frente a un cambio importante, hemos de suponer que estos requisitos no se iban a cumplir a falta de maestras preparadas. Sin embargo la ley se promulgó, y en caso de que la familia de alguna niña optase por que su hija aprendiera a leer, lo más probable es que la maestra tuviera que recurrir a un pasante. ${ }^{10}$

Cuando en 1823 recobra el poder Fernando VII, ayudado por los franceses, la primera medida que toma es derogar el Reglamento de 1821. De las Primeras Letras se ocupó el Real Decreto de 16 de febrero de 1825, que pretendía fomentar establecimientos donde las jóvenes recibiesen la cultura general de las clases acomodadas. A consecuencia de este trabajo nacería el Plan y Reglamento de Escuelas de Primeras Letras de 1825, por el que se establecen cuatro clases de escuelas que impartían una instrucción gradualmente menor. Ahora, a la clase social de la maestra al frente de los cuatro tipos de escuelas, se añadían las limitaciones que suponía su insuperable condición femenina. Así, en cada una de las escuelas establecidas según el reglamento de 1825 , los conocimientos y sueldos de las maestras iban a ser diferentes y, por supuesto, inferiores a los del maestro.

Se trataba de educar a las niñas en los rudimentos de la "Fe católica, en las reglas del bien obrar, en el ejercicio de las virtudes y en las labores propias de su sexo" (art. 197). Las juntas quedaban encargadas de elegir a las más timoratas e instruidas en las materias que se les confiaba (art. 200). Aquéllas que regentaran escuelas de primera y segunda clase debían realizar un examen ante las juntas de la capital; mientras que las de tercera y cuarta serían examinadas en sus respectivos pueblos.

En el reglamento de 1825, la lectura aparece como un punto de apoyo, por tanto secundario, en la formación de las maestras - de hecho solo se les enseñaba a leer en los catecismos (Ruiz Berrio 1970, p.30) - mientras que en 1821, la lectura se había intentado incluir en el curriculum de las niñas como contenido básico. En el caso de que la maestra supiera leer y escribir caso poco corriente -, quedaba encargada de enseñar este arte a las niñas; de lo contrario, un maestro o pasante, mayor de cuarenta años, se ocuparía de estas asignaturas (art. 199); esta idea había aparecido ya en el Reglamento de 1821. Las autoridades, que decidieron tomar medidas para prevenir posibles relaciones afectivas en el aula, fueron abrigando, al lado de fuertes intereses, serios prejuicios que llevarían al legislador a delegar en los padres y tutores de las niñas la decisión de dotarles de una formación más esmerada (art. 199). Este es uno de los puntos donde quizás se percibe con mayor claridad la regresión histórica que supuso este reglamento. 
El interés de Fernando VII, al regular los criterios para proceder al asentamiento de escuelas primarias y escolarizar a la población femenina, no era otro que afianzar el control ideológico sobre la mujer; ${ }^{11}$ que estaba asegurado al eliminar esas oposiciones, donde supuestamente las maestras deberían mostrar conocimientos más o menos lindantes con el campo científico o productivo. Esa idoneidad exigida a las maestras, que juzgarían unos organismos más que sospechosos, era medida por unos criterios muy acordes con el sentir de la época, que sumergió a la mujer en un prolongado estado de minoría de edad.

\section{La maestra maternal (1838-1876)}

La maestra maternal (segundo modelo de maestra que aparece en paralelo con el surgimiento de las escuelas de párvulos) ${ }^{12}$ se establece en España a partir de las iniciativas llevadas a cabo por Montesino $(1781-1849)^{13}$ como consecuencia del cambio político y social que produjo el triunfo de la revolución burguesa (Scanlon 1982). Este modelo desarrolla su actividad en la primera fase de la revolución industrial, primera mitad del siglo XIX. Las escuelas de párvulos en España comienzan a aparecer para resolver una cuestión social y atender las necesidades de la clase obrera. La difusión de este modelo, que inicialmente sólo existía en Inglaterra, Infant Schools, pasa por tres fases: en Inglaterra se produjo hasta 1820; en Francia de 1820 a 1830; en el resto de Europa, desde 1830 a 1840. De esta manera en Francia aparecen en 1826, en Italia en 1828, en Hungría en 1837, en Suiza en 1827 , en Dinamarca en 1828, en Checoslovaquia en 1832, en Alemania en 1830, en Estonia en 1839, en Portugal en 1834, en Polonia en 1839 y, finalmente, en España en $1838 .^{14}$

\section{Justificación teórica del modelo de maestra maternal}

Hasta ahora las afinidades entre Rousseau y Kant han sido empleadas para esbozar las bases de lo que he denominado maestra analfabeta, las discrepancias entre ellos, que creo no han sido tratadas, serán de gran utilidad para comprender la mentalidad social que justifica este nuevo modelo. La dicotomía cultura-hombre/naturaleza-mujer, defendida por ambos, me ha servido para explicar la aparición del primer modelo; ahora una nueva dicotomía, bello/sublime, me va a permitir fundamentar el segundo.

Cuando Kant analiza el contenido de la naturaleza de la mujer se muestra más comprensivo, menos duro que Rousseau. Si para Rousseau la mujer 
es "aquella Circe enigmática que convertía en cerdos a los hombres, haciéndoles regresar a sus instintos, a su naturaleza animal"(Molina Petit 1992, p.11), Kant muestra, ahora sí, su total desacuerdo con esta afirmación. Según él, la naturaleza del sexo bello no sólo no supone un peligro para conseguir la armonía social que conduce al progreso, sino un elemento de complementariedad muy necesario y útil para alcanzar el progreso social. Las diferencias naturales que presentan los sexos comienzan a apreciarse, según él observa, desde edades tempranas; pues, a diferencia de los niños, las niñas tienen dominio de sí a una edad en que "nuestra juventud masculina bien educada es todavía indómita, torpe y apocada, son muy sensibles para advertir la más pequeña falta de atención y de respeto hacia ellas, tienen el fundamento principal del contraste en la naturaleza humana de las cualidades bellas con las nobles".

En total desacuerdo con Rousseau, Kant afirma que la influencia femenina es necesaria y positiva porque a la mujer, además de la finalidad impuesta por la naturaleza de conservar la especie, la naturaleza le ha confiado, dada su sensibilidad para lo bello, la tarea de refinar la sociedad. Su misión consiste en pulir al sexo sublime en asuntos estéticos, y exhortarle a la moralidad por vía del sentimiento de lo bello, que es a priori en ella. Pues bien, este es un argumento llave para comprender, por ahora, el modelo de maestra maternal. Desde el momento en que Kant admite que la influencia de la mujer es positiva está cuestionando un problema no sólo de índole natural sino también social, porque el efecto que ejerce la madre en el núcleo familiar se extiende pronto, a través de ese germen depositado en las generaciones venideras, sobre la sociedad en su conjunto. La brecha abierta por él me servirá de eje para fundamentar, por ahora, el modelo de maestra maternal.

Kant, uno de las máximos representantes de la burguesía de su tiempo, aboga por el matrimonio; unión perfecta, complementaria donde cada uno aprende del otro aquello de lo que carece. El maridaje no se produce por la necesidad imperiosa de que el hombre ponga freno a las pasiones de la mujer, tal como apuntaba Rousseau, al contrario, la unión de lo bello con lo sublime permite que la pareja se constituya en una persona moral única "animada y regida por la inteligencia del hombre y el gusto de la mujer" (Kant 1990, pp. 67-67 y 86). La inteligencia del hombre es sublime, pero no bella; la de la mujer es bella y nunca puede llegar a ser sublime; diferencias que vienen marcadas por la naturaleza, no por la sociedad. El descubrimiento de atractivos morales entre el hombre y la mujer constituye la primera base de un buen entendimiento, antesala del matrimonio. Kant, que afirma no querer desconocer la primorosa diferencia que la naturaleza ha tenido a bien establecer entre las especies humanas, encuentra en esta unión el escenario social idóneo 
donde cada sexo puede representar sus papeles aprendiendo del otro. La mujer "amplía" su sentimiento moral gracias al contacto con la inteligencia sublime; el hombre pule sus costumbres por la influencia positiva que recibe del sexo bello. En esta unión uno debe doblegarse al otro, y siguiendo la ley de la naturaleza, según él, el más débil, la mujer, se somete al más fuerte, el hombre. A él le toca mandar y a ella "dominar", porque la "inclinación domina y el entendimiento rige" (Kant 1991, pp.261-262).

El argumento utilizado por Kant, que justificó la influencia positiva de la mujer sobre el hombre, tiene un enorme valor para entender la demanda en el aula de una maestra, necesaria por su naturaleza de bello sexo, complementario e inferior, pero, al fin y al cabo imprescindible en el espacio público. Si la mujer es necesaria como complemento en el hogar, también lo será en el aula donde aporta las cualidades femeninas de las que el hombre carece. En la misma medida que ambos son necesarios en el espacio doméstico, serán igualmente imprescindibles en el aula como complemento moral, que no cultural - planteamiento que excusa a la mujer de recibir una educación más elevada. De esta manera, la presencia de la maestra maternal en sus comienzos es necesaria en la escuela para cubrir esas lagunas producidas por las diferencias naturales.

\section{Influencia de Pablo Montesino}

A partir de 1834 comienza a configurarse en España un sistema de educación nacional. La intervención del Estado en materia educativa provocará una fuerte demanda de las escuelas y agentes educativos necesarios para cubrir los nuevos requisitos escolares. Ante esta situación, y para resolver el problema presupuestario que supone contratar al número necesario de docentes y abrir las escuelas de niños que ordena el legislador, los gobernantes deciden iniciar la inclusión de la maestra española en las escuelas públicas de niños, y tiene lugar su segunda fase de incorporación en el sistema educativo y el primer momento de inclusión en las escuelas de niños. Sin embargo este proceso de incorporación se inicia tímidamente, pues, en principio, la presencia de este modelo de maestra en el aula resulta imprescindible porque ayuda a cubrir las lagunas que el hombre, por su naturaleza masculina, es incapaz de abordar.

(...) contando nuestras escuelas de párvulos de 200 niños por término medio, no tiene la mujer fuerza, ni carácter, ${ }^{15}$ ni posibilidad bastante para dirigir estos establecimientos, que necesitan la energía del 
hombre si ha de existir una organización que permita, si no la educación, porque es muy difícil, al menos la estancia de los niños con alguna comodidad y con el orden posible. ${ }^{16}$

En opinión de Montesino, la maestra, al igual que la madre en el hogar, estará subordinada al maestro porque se considera "naturalmente más capaz de cuidar la salud, el aseo y el alimento de los niños. Montesino justifica está dependencia excusándose, nuevamente, en el destino biológico de la mujer, la maternidad, "su delicadísima organización y sus padecimientos frecuentes" le permiten justificar las funciones de dependencia y subordinación que exige de estas profesoras. La escuela asegura la reproducción de esa estructura patriarcal donde el maestro asume, igual que el padre en la familia, un papel de poder y autoridad; la maestra, como la madre en el hogar, se dedica al cuidado maternal de niños y niñas en el espacio publico. En efecto, la maestra maternaldebe llenar en la escuela, a modo de exigencia social, el espacio femenino asignado a las madres. Su presencia en el aula es imprescindible porque aparece como la madre social que sustituye a la biológica. De ahí que para ejercer sólo se le pidiera un fuerte sentimiento maternal, eso sí, reforzado con esa serie de conocimientos mínimos, todos ellos relacionados con el mundo de la infancia. Las maestras, siempre que fuese posible, debían someterse a un examen para poder ejercer; pero este paso no era necesario, como en el caso del maestro. Una buena maestra es ahora la que cuida a los niños con amor maternal, vigila el aseo e higiene, supervisa las comidas y hace las observaciones oportunas a la persona que lleva al niño a la escuela "con mucha moderación y buen tono". Al maestro, sin embargo, se le exige un curriculum de mayor calidad que contiene, además de las materias de lectura, escritura y las cuatro primeras reglas elementales de la aritmética, nociones de geometría, gramática castellana, geografía e historia y facultades musicales; precisando que en caso de no ser portador de estos conocimientos al comenzar su profesión deberá mostrar ser bastante despejado para adquirirlos por sí mismo al tiempo que las enseña (Montesino 1840, pp.7-9, 34, 53).

Muchas excusas y prejuicios, reflejo de la sociedad patriarcal de su tiempo, que no hacen más que ocultar la causa principal que propicia este primer momento de incorporación de la maestra española a la escuela pública de niños. ¿Qué se puede hacer para mantener quietos a 200 niños y niñas de diferentes edades encerrados en un habitáculo durante un cierto número de horas? Pues echar mano de alguien que ha cultivado la paciencia necesaria para aguantar a semejante multitud, y la mujer tiene bien desarrolladas esas características porque ha estado dedicada en exclusiva al cuidado de la infancia en el hogar. 
La maestra maternal, que queda subordinada al maestro, viene a resolver un problema económico; ya que pagando un solo sueldo, el del maestro, se consiguen dos agentes educativos por el precio de uno; tesitura que será muy aprovechada por los ayuntamientos tras promulgarse el Plan de Instrucción Primaria de 1836, que obligaba a abrir escuelas de niños en España. No cabe la menor duda de que Montesino era un hombre práctico, comprometido en materia política, que conocía bien los problemas presupuestarios por los que atravesaba España y encontró la forma de solucionar, al igual que se venía haciendo en otros países, la demanda de escolarización que se estaba produciendo.

El modelo de maestra materna/propuesto por Montesino encierra distintas categorías, que se van a distinguir tanto por el nivel de conocimientos exigidos a la profesora, como por la preparación del maestro al que ayuda y el número de párvulos con que se enfrenta. En primer lugar, se encontraba la maestra que podía tener a su cargo grupos reducidos que no excedieran de 40 alumnos. Ahora bien, reconocido este pequeño espacio de autonomía, Montesino muestra su desconfianza por el tipo de trabajo que pueda desempeñar una maestra sola. De ella, según él, no se puede esperar que los adelantos de los niños sean "por lo común grandes", ni que los pequeños de 4 a 6 años lleguen a estar tan bien disciplinados. Una segunda categoría de maestra sería la de la "esposa, madre, hermana o criada que ayudaba a un maestro de mediana edad" a manejar grupos de 120 a 140 alumnos. Después, se encontraba la maestra que asistía a "un maestro de superior habilidad" en clases de 150 a 200 párvulos. Por último, el maestro y la maestra de párvulos, ayudados por una criada, podían afrontar grupos de hasta 250. Así se hizo. Dependiendo de las necesidades de escolarización y de los medios económicos de cada municipio se optó por un modelo $u$ otro.

Ahora bien, ¿de dónde proceden esos modelos que Montesino aplica para crear las escuelas de párvulos en España? Aunque este asunto no esté suficientemente tratado, y no es este el momento de abordarlo con la profundidad que el tema merece, es necesario indicar que estas escuelas están copiadas de las Infant Schools inglesas; de donde se inspiraron igualmente las salles d'asile francesas. ${ }^{17}$

\section{La maestra maternal en la legislación}

\section{La maestra maternal en su primera fase}

Cuando los progresistas llegan al poder en 1836 se promulga el Plan de Instrucción Primaria de 4 de agosto de 1836, que obliga a los ayuntamientos 
a abrir escuelas para niños, al tiempo que, como veremos, restringía la apertura de las de niñas.

El legislador ofrece todo tipo de detalles en lo referente a las escuelas de niños; de las de niñas sólo se dice que se establecerán si los "recursos lo permiten", y, en el caso de que económicamente esto fuera posible, "se acomodará la enseñanza en estas escuelas a las correspondientes elementales y superiores de niños, pero con las modificaciones y en la forma conveniente al sexo". El legislador promete que el establecimiento de estas escuelas, su régimen, gobierno, provisión de maestras etc. serán objeto de un decreto especial (art. 21); que por cierto nunca llegó a aparecer.

El legislador, que había obligado a abrir escuelas de niños, se vio comprometido, en coherencia con tal decisión, a asegurar la formación del maestro. Esta decisión abre un paréntesis oficial que, al tiempo que legitima una formación académica en las escuelas normales masculinas, niega a la maestra un derecho que reserva al hombre; así, la maestra, sin preparación académica previa, no ofrecía la garantía necesaria para desempeñar con profesionalidad su trabajo, y acompañaba al maestro cuando ejercía en las escuelas de niños

Los moderados, de nuevo en el poder en 1838, bajo la presidencia del Conde de Ofalia, decidieron llevar a cabo un proyecto de Ley sobre el que asentar las bases de la nueva enseñanza liberal. El Plan de Instrucción Primaria de 21 de julio de 1838, que sigue los principios básicos de los textos anteriores, sobre todo el de 1836, y acuña los principios del liberalismo moderado en materia de educación, es un documento educativo de gran importancia, que influyó decisivamente en la redacción del Plan Pidal de 1845 y la Ley Moyano de 1857. El Gobierno, que pretendía llenar el absoluto vacío existente hasta entonces en materia de instrucción pública, puso todo su empeño en mejorar e impulsar la formación del maestro (Peset 1974, p. 560).

El gobierno, que parece preocupado por controlar todos los niveles de la enseñanza, indica, por primera vez, la conveniencia de establecer escuelas de párvulos (art. 36). El asunto, promovido por Montesino, que tomaba parte de la Comisión especial para formar esta clase de establecimientos, ya había sido planteado por el Gobierno dos años antes, 1836; momento en el que se publicó una circular, con fecha de 22 de agosto, que encargaba a los jefes políticos de las provincias la labor de promover la creación de escuelas de párvulos según el reglamento e instrucción que se les remitía. En adelante, el número de escuelas de párvulos que se iban a establecer superaría las provisiones y expectativas del legislador; coyuntura que iba a favorecer la demanda de maestras en este sector. 
Los modelos de reforma educativa propuestos por Montesino se incorporaron a los folios de la legislación española. El modelo de maestra maternal se refleja con absoluta claridad en el Reglamento de Escuelas Públicas de Instrucción Primaria Elemental de 26 de Noviembre de 1838, que indica la conveniencia de que los maestros,

por medio de sus mujeres unos, y otros valiéndose de sirvientas idóneas, agregasen en el mismo edificio, aunque en salas separadas, una escuela de párvulos o una de niñas, a la elemental de niños; sin que en ningún caso deba el maestro desatender ésta por un sólo momento, pues en ello faltaría al principal objeto de la instrucción, y correría el riesgo de que ni una, ni otra escuela estuviesen cuidadas debidamente. (...) El maestro podría en las horas que no son de la escuela, y en conferencias domésticas, instruir suficientemente a estas maestras; y podría también variar las horas para estas clases particulares, y cuidar en parte de ellas".

En la sala de la escuela, y a la vista de los niños, debía figurar una imagen de Jesucristo Señor Nuestro (art. 4). El Reglamento concede una prioridad absoluta a la enseñanza moral y religiosa (art. 38); la intelectual, muy acorde con los criterios de Montesino, queda postergada a un segundo plano.

Un año más tarde, en 1839, se publica el primer reglamento de exámenes para optar al título. ¿Qué tratamiento se da a la maestra? Se dice que pase las correspondientes pruebas ante las Comisiones provinciales pero, conocedores de su escasa formación, añaden: que no sean públicas. Se trata, además de un detalle para con la timidez femenina, de tapar defectos; al menos, ya sentían vergüenza. ¿De qué examinan a las maestras? De religión y moral, lectura y escritura, cuentas por números enteros y labores de utilidad para las familias pobres. ¿Y a los maestros? A éstos se les exigen mayores conocimientos de aritmética, elementos de gramática castellana, sistemas y métodos de enseñanza; además podían optar, a diferencia de la maestra, al grado superior.

Por Real Ordem (R.O.) de 1 enero de 1839 se ordenaba que las maestras tuvieran 25 años de edad, y fuesen personas "de habilidad conocida en todos los ramos de la instrucción que se da en el colegio, de salud robusta, de carácter afable y de buenos modales". Si las nombradas hubieran recibido su educación en el colegio podrían comenzar a ejercer a los 21 años. (La diferencia de edad que se marca muestra la preocupación inicial de estos hombres por 
dotar a estas profesoras de cierta preparación, aunque fuese mínima. Y, en fin, algo es algo, por poco que fuera). El sueldo que se fija para la maestra es de 20 reales anuales, además se le ofrece habitación y comida en el colegio (art. 59). El número de maestras, según la ley, no podía exceder de 1 por cada 20 niñas (art. 55).

El Real Decreto de 23 de septiembre de 1847, que dicta nuevas normas para impulsar la instrucción primaria, ordena que la maestra reciba una tercera parte menos del sueldo que obtenía el maestro; sólo en el caso de acceder mediante oposición podía aproximarse a la dotación mínima que cobraba el maestro. Los individuos de la Comisión superior, un profesor y dos maestras acreditadas, elegidas por el jefe político, se encargarían de valorar su idoneidad (art. 29). La Ley de 1847 establece una edad para obtener plaza en calidad de propietario, que baja de 25 a 22 años en el caso de las mujeres, mientras que para los hombres se fija en 24 (art. 30). Este dato debe considerarse un paso importante, pues va a posibilitar la incorporación de la mujer a la enseñanza, vía facilidad en el acceso; lo cual será de gran utilidad a un Estado que se encuentra, después de 1857, ante el deber de afrontar la nueva exigencia de escolarización de la población infantil femenina. Más adelante, la propia reina, preocupada por la educación de esas futuras madres y esposas, pidió a la Comisión Superior y al inspector de instrucción primaria de cada provincia que diesen cuenta todos los meses de los adelantos conseguidos en este asunto; y tampoco se olvidó de recordar al Gobierno su responsabilidad sobre los ayuntamientos en el tema (R.O. de 20 de diciembre de 1852).

Posteriormente, en 1850, se dicta un nuevo reglamento que ordena que los exámenes de las maestras no sean públicos y regula el acceso al título superior de maestra. Demasiada severidad si tenemos en cuenta que los maestros se formaban en Escuelas Normales y las maestras no. ¿Qué se le pedía a ellas? Los conocimientos de aritmética, geometría, geografía, agricultura y métodos de enseñanza, necesarios para obtener el título de maestro en el nivel elemental, se sustituían, en el caso de la maestra, por conocimientos de cuentas y labores de inmediata utilidad a las familias - ambos muy necesarios para formar una buena profesional del hogar -. En cuanto al nivel superior, existían materias comunes, al igual que para el elemental (en éstes las materias eran lectura, escritura, religión, gramática, ortografía castellana; a las que sumaban, para el nivel superior, aritmética, geometría, dibujo lineal y geografía e historia de España); sin embargo, la física, química e historia natural, necesarias para obtener el título superior de maestro, eran reemplazadas, en el caso de la maestra, por pruebas de habilidad para las labores de utilidad y adorno $^{18}$ (las labores exigidas para cada uno de estos niveles reflejan 
importantes barreras de clase. Así, cuanto más elevados eran los estudios a realizar por las niñas, más distinguidas serían las labores que las maestras les enseñaban (Apple 1986)).

El detalle con que el legislador describe las materias a cursar por las maestras induce a pensar que nos encontramos ante un cambio importante. Pero, desgraciadamente, una cosa era la teoría y otra la práctica. El testimonio de Gil de Zárate prueba que las maestras permanecían casi en la misma ignorancia que antes, que el examen, de "una indulgencia vituperable", no ofrecía ninguna garantía de su idoneidad. El saber de las maestras se seguía midiendo por el primor que mostraban con las labores de su sexo, "talento a la verdad importantísimo en ellas", pero la triste realidad es que "muchas no sabían escribir, ni leer". Lo cierto es que él era el principal culpable de esa situación, porque convencido de que el magisterio era una carrera para el hombre, pero no para la mujer, se negó a permitir durante su mandato que "jóvenes adultas" permanecieran "encerradas" en centros que, a su entender, podían "atentar contra la moralidad", indicando que el "aumento de gastos era quizá el menor de los obstáculos" para proceder a la apertura de Escuelas Normales de Maestras. Como buen político se armó con todo tipo de razones para excusar su decisión, e intentó justificar que las mujeres de esa edad eran más necesarias a las familias pobres que los hombres, y que, además, no había demanda para que sus hijas trabajaran fuera de sus casas cuando podían ganar más con el trabajo manual. Motivos por los cuales, según él, las Escuelas Normales de Maestras estarían poco concurridas (que es lo mismo que decir que le estaba ahorrando gastos inútiles al Estado). Su propuesta era que los Institutos religiosos se encargasen de formar a las maestras (Gil de Zárate 1855, pp.366-371).

La R.O. de 11 de enero de 1853 - vigente en todas sus partes en virtud de otra de 11 de mayo de 1876, que únicamente derogaba la limitación de tener 24 años para poder ejercer, al no poner limitación de edad - exigía acreditar a todo aspirante a maestro de párvulos buena conducta moral y religiosa, ser casado y hallarse en disposición de ejercer el cargo de maestra o ayudante la esposa u otra mujer de la familia. De esta manera, los vínculos de parentesco más inmediatos aseguraban ese cálido ambiente familiar que debía irradiar el aula escolar.

\section{La maestra maternalen su segunda fase}

No deja de llamar la atención que el interés por instruir a la mujer que, es obvio, va a sufrir las modificaciones que corresponden con el paso 
del tiempo -, no cambiase substancialmente el modelo de maestra maternal hasta 1876. Por supuesto que este modelo padeció modificaciones importantes (durante este período aparecería una de las leyes más duraderas, la Ley Moyano, que, por primera vez en la historia, se preocupaba del asunto de la preparación de las maestras). Efectivamente, en los 19 años que median entre la ley del 38 y la del 57 se produjo un reemplazo en la administración española (en 1851, Gil de Zárate, que había sido encargado de los asuntos de instrucción pública en 1844, es sucedido por otros) y los intereses del legislador ya no eran los mismos. La influencia de Montesino - que a imitación del sistema inglés, donde aún predominaba el magisterio de los hombres en las escuelas, consideraba necesaria la presencia de un maestro y una maestra en el aula infantil - se había atenuado ante la aparición de una nueva situación: en los países colindantes con el nuestro (Francia, Inglaterra, Italia, etc.) había maestras al frente de la educación de las niñas. A la causa administrativa se sumaba así la política, y el modelo de maestra maternal sufrió cambios importantes tras la promulgación de la Ley Moyano.

Efectivamente, con la promulgación de la Ley Moyano de 1857, que afianza el modelo de maestra maternal, tienen lugar importantes cambios en este segundo modelo. Según el artículo quinto de la ley, las niñas, futuras trabajadoras domésticas, no necesitan estudiar esas breves nociones de agricultura, industria y comercio, según las localidades; ni, tampoco, los principios de geometría, dibujo lineal y agrimensura; y las nociones generales de física e historia general "acomodadas a las necesidades más comunes de la vida". La intención de Moyano es ayudar a la mujer a realizar, con más eficacia, las eternas obligaciones sociales a las que se encuentra condicionada por su papel de reproductora biológica y moral de la especie. Es decir, que la mujer sigue siendo ese bello sexo, inferior y supeditado al hombre del que nos hablaba Kant; la única diferencia es que ahora, precisamente por esa influencia como educadora y madre tan señalada por Kant, necesita cierta instrucción pública.

El desigual tratamiento que reciben las niñas repercute de manera directa en la formación de las maestras; pues con la estatalización de estas profesoras se relega, ahora a través de un curriculum oficial, la educación de la mujer al ámbito doméstico. Moyano, al regular por ley las asignaturas a cursar las maestras aspirantes al grado elemental y superior, consolidó el modelo de maestra maternal. Así, mientras que para obtener del título de maestro elemental era imprescindible cursar catecismo explicado de la doctrina cristiana, elementos de historia sagrada, lectura, caligrafía, gramática castellana con ejercicios prácticos de composición, aritmética, nociones 
de geometría, dibujo lineal y agrimensura, elementos de geografía, compendio de la historia de España, nociones de agricultura, principios de Educación y métodos y práctica de enseñanza; para conseguir el de maestra elemental, era mas que suficiente con aprender doctrina cristiana y nociones de historia sagrada, lectura, escritura, gramática y ortografía castellana, principios de aritmética y labores propias de su sexo (La religión y las materias relativas a la alfabetización la capacitaban para desempeñar el trabajo de maestra en el ámbito privado, mientras que las labores serían de gran utilidad a la economía doméstica). A los maestros aspirantes al título superior se les exigía principios de geometría, dibujo lineal y agrimensura, rudimentos de historia y geografía, especialmente de España, y nociones generales de física e historia natural, acomodadas a las necesidades más comunes de la vida. Nuevamente, para las maestras aspirantes a las escuelas superiores de niñas, todas estas materias científicas, a excepción de historia y geografía (que sería de utilidad para el exiguo número de niñas de clases elevadas que cursaran estos estudios), eran sustituidas por elementos de dibujo aplicado a las labores y ligeras nociones de economía doméstica.

La Escuela Normal Central de Maestras, que se crea por R.O. dictada por Isabel II, el 24 de febrero de 1858, con carácter central del reino, ${ }^{19}$ y bajo la inmediata vigilancia e inspección de la Junta de Damas de Honor y de Mérito y de la curadora nombrada por las mismas, nacía en respuesta al interés de un Estado que comenzaba a interesarse por controlar esa influencia, preconizada por Kant, que la mujer ejerce desde el hogar sobre la sociedad en su conjunto. Se trataba de ofrecer una orientación uniforme para obtener un comportamiento del que se esperaba mucho: un modelo de ciudadana acorde con las exigencias políticas y sociales del momento. De esta manera, su apertura en Madrid, tan aplaudida por esperada, se producía al rebotar sobre las maestras el principio de obligatoriedad de escolarización de la población infantil regulado por Moyano, que incluye por vez primera a las niñas. La Escuela Normal Central de Maestras daba vida a un agente social capaz de satisfacer las demandas de escolarización de la infancia en edades tempranas - inquietud que nace en la década de los treinta.

A la mujer que aspirase a ser maestra - principal vía de acceso a un trabajo cualificado que se ofrecía a la mujer a mediados del XIX - se le permitían dos opciones (art. 170). La primera, realizar estudios de maestra en la Escuela Normal Central, era sin duda la más atractiva, tanto por el privilegio que suponía ser alumna del único centro oficial reconocido por el Estado, como por las ventajas profesionales de las alumnas procedentes de la Normal de Madrid, cuyo título les capacitaba para ocupar todo tipo de plazas en los establecimientos 
docentes de España, incluso el de Directora; pero, también era la más inasequible tanto por el acceso, de evidente dificultad, como por la escasez de plazas, el coste, la lentitud de medios de desplazamiento y la precaución de las familias a perder el control moral sobre sus hijas al permitirles instalarse en Madrid. La segunda solución, que se presenta más asequible tanto para aquellas familias con menos recursos económicos, como para las que no residieran en las cercanías de aquél Madrid, abrigaba la posibilidad de ser maestra realizando estudios privados; que no eran ofertados en instituciones privadas, pues no existían, sino de un modo particular o doméstico, por su cuenta, o sea, el sistema tradicional de formación propuesto por Montesino. Esta alternativa, que permitía a las familias ejercer un mayor control moral sobre sus hijas, desvía a las aspirantes a maestra hacia ese sector que tanto favorece la ley: la enseñanza privada religiosa (art. 156). En efecto, Moyano no sólo permitió que ejercieran la enseñanza personas sin la más mínima garantía de idoneidad, sino que, además, dio luz verde para que las escuelas normales de maestras que ya estaban establecidas ante de decretarse la ley, así como las que se fueron asentando después, funcionasen a sus anchas, sin doblegarse a un curriculum uniforme y sin ninguna clase de vigilancia, aunque en teoría se supone que eran visitadas por los inspectores (en 1867 había 29 escuelas de maestras y 48 de maestros establecidas en España). La situación empeoraba, porque el legislador volvía a confiar en la iniciativa privada de unos hombres, repletos de prejuicios y escasos de educación, la formación del sexo contrario.

\section{La maestra racional intuitiva (1868-1882)}

La maestra maternal defendida por los políticos moderados comenzó pronto a mostrar las arrugas producidas por el paso del tiempo; trance que llevó a los reformadores de la época a buscar otra pareja femenina más acorde con los principios del respecto, la libertad, el desarrollo y la igualdad que imponía el nuevo orden social. España se abre a Europa para afrontar el reto que supone transformarse en un país moderno en el orden capitalista; apertura necesaria para mejorar su nivel industrial, financiero y educativo. Este es el momento en que Sanz del Río introduce el krausismo en nuestro país; movimiento filosófico importado de Alemania que configura el trasfondo político-social de la Revolución de 1868; situación que iba a ocasionar importantes cambios sociales, educativos, metodológicos y religiosos durante el último cuarto del siglo XIX. A consecuencia de todo ello, el nivel académico exigido a la maestra se fue alejando - gracias al impulso producido por la iniciativa privada - de los límites académicos regulados por Moyano; $y$, al tratar de adaptar el sistema educativo a las necesidades sociales, causadas por el propio curso del desarrollo his- 
tórico, las diferencias entre el proceso de formación femenino y masculino se fueron, poco a poco, aminorando. Las necesidades políticas, sociales, educativas y religiosas que provoca la nueva coyuntura iban a acarrear importantes giros en la rueda del progreso social, desencadenando cambios muy favorables al tránsito hacia el tercer modelo de maestra.

No deja de resultar significativo que los cimientos ideológicos que producen el giro hacia el nuevo tipo de maestra, inspirado ahora en la filosofía krausista y la metodología freoebeliana, sean una réplica alemana (Ossenbach 1982, pp. 308-318), mientras que la teoría que dio lugar al modelo de maestra maternal propuesto por Montesino estaba copiada de las Infant Schools inglesas. Es decir, dos países europeos muy diferentes entre sí, Alemania e Inglaterra, resultan un marco de referencia necesario para comprender los modelos de maestra propuestos por liberales moderados e institucionistas regeneracionistas en España.

Ahora, me gustaría definir brevemente lo que entiendo por este nuevo modelo. Este término hace referencia a una profesional de la enseñanza formada en Escuelas Normales de Maestras, cuyo asentamiento en provincias no fue regulado hasta 1877 (es importante recordar que en 1857 Moyano tan sólo obligó a abrir la Escuela Normal de Maestras de Madrid, limitándose a recomendar a las provincias a establecer esta clase de establecimientos), a quien se le exige un curriculum cualificado en consonancia con las nuevas demandas sociales que emergen en España, y una metodología, la froebeliana, apropiada para intuir la naturaleza infantil, que se presenta muy compatible, en su opinión, con lo que entienden, y exaltan, como cualidades específicamente femeninas. La maestra racional intuitiva significó la tercera fase de su incorporación a la escuela pública, y su segundo momento de inclusión en las escuelas de niños.

Los términos elegidos para definir este tercer modelo, conceptos que encierran una evidente contradicción, pretenden reflejar en qué medida el derecho de la mujer a la instrucción quedó fuertemente limitado por la función biológica femenina. Efectivamente, aunque los krausistas y los froebelianos españoles consiguen crear un campo de opinión favorable a la instrucción de la mujer, el curriculum que proponen para maestras y maestros continúa presentando diferencias importantes.

\section{Justificación teórica}

Volveré a retomar el hilo de la argumentación empleada en los modelos anteriores para señalar las bases teóricas del nuevo modelo de maestra. 
Veamos. Junto con los planteamientos expuestos por Rousseau y Kant, a quienes considero representantes del sentir de la mayoría, se produjeron, no por atípicos menos importantes, algunas contribuciones notables en defensa de la educación femenina que apuntaban como social, que no natural, el origen de las diferencias entre los sexos. Condorcet, convencido de que las desigualdades, a las que considera de origen social, se producen fundamentalmente al actuar la maternidad en la mujer como límite biológico a su actividad social, considera que las visibles desemejanzas entre los sexos son tan sólo el resultado del interés dominante de una época que al alzar al hombre como protagonista del progreso social ha relegado a la mujer a la esfera del hogar. En su obra están trazadas las líneas teóricas del modelo de maestra racional intuitiva. La referencia a su legado resulta de gran utilidad para comprender el principio de igualdad y democracia que encierra el modelo de maestra que aparece en España a lo largo de la segunda mitad del siglo XIX.

Condorcet es muy consciente del peligro que supone para el progreso relegar a la mujer en la esfera privada y doméstica. La desigualdad es como un virus que se extiende con rapidez. Si a la mujer se la excluye de un derecho que se reserva al hombre, la instrucción, el espíritu de desigualdad que se conservaría entonces en un sexo se extendería bien pronto a los dos. En opinión de Condorcet el Estado tiene el deber de hacer posible la igualdad entre los sexos, ofreciendo a las mujeres el derecho a recibir la misma educación que los hombres. A su entender, los derechos naturales de hombres y mujeres son inalienables y anteriores al Estado; razón suficiente para que éste garantice, en virtud de una igual instrucción pública, el desarrollo de las disposiciones naturales de ambos sexos. Condorcet acaba de dar un paso decisivo. Pero va más allá. Por supuesto que hombres y mujeres presentan diferencias notables, pero el origen de tales desigualdades se encuentra en el proceso de socialización al que hombres y mujeres han sido sometidos: " ... no es la naturaleza, es la educación, es la vida social la que causa esta diferencia. (...) Han acostumbrado a las mujeres a la idea (...) de lo que es honesto (...), es tan razonable para una mujer ocuparse del adorno de su figura como lo era para Demóstenes el cuidar su voz y sus gestos" (Condorcet 1993, p.103). Acaba de poner el dedo en la llaga.

La moralidad tan proclamada por Kant sufre el ataque directo de Condorcet. Las madres, más tarde las maestras, reproducían en sus hijas, mediante la educación doméstica, la tradición de unos comportamientos virtuosos, sentimentales, bellos y abnegados; de esta manera, se aseguraba el estado de dependencia y analfabetismo femenino. Condorcet, que denuncia el sometimiento de la mujer al varón como algo negativo, hace notar que la igualdad 
entre hombres y mujeres no será viable si se niega a la mujer el derecho a participar en la vida pública por medio de leyes; la mujer deberá recibir la misma educación pública que el hombre. Rousseau y Kant hablaban de lo que veían: desigualdad, inferioridad, dominación etc., pero las razones que producen este hecho son, según Condorcet, sociales, que no naturales.

Condorcet es muy prudente al reconocer que su condición de hombre le deja en desventaja para ganarse la confianza del sexo femenino: "Desde que Rousseau afirmó que sólo estaban hechas para cuidarnos y sólo eran aptas para atormentarnos, no debo esperar que declaren estar a mi favor". Efectivamente, Rousseau y Kant, al reducir el trabajo de la mujer a las tareas de reproducción de la especie no sólo limitaron la competencia entre hombres y mujeres, sino que obstaculizaron el camino hacia la paz, el progreso y la felicidad. A diferencia de Rousseau y Kant, Condorcet, que se alza partidario de que la mujer reciba una educación pública, se muestra convencido de la capacidad del sexo femenino para actuar según principios propios, sin necesidad de que le vengan dictados por el hombre. Por ello, no duda en advertir de los peligros que supone para el progreso castigar a la mujer a permanecer relegada a la esfera privada y doméstica; una mujer instruida supone para él un complemento añadido ya que puede desempeñar la función de maestra en el hogar. La experiencia de la maternidad hace posible que la mujer responda, en su función de maestra pública, a las dificultades que se pudiesen plantear con los niños porque "el arte de enseñar se adquiere con el uso y se perfecciona con la experiencia", así, si a la experiencia le añadimos la necesaria instrucción obtenemos como resultado una maestra concienciada con su trabajo.

La mujer, que cuida de niños y niñas durante los primeros años, conoce mejor que nadie la naturaleza infantil al haber dedicado gran parte de su tiempo a tratar con la infancia en el hogar; lugar donde ha desarrollado esas cualidades tan apropiadas, fruto de su experiencia maternal, para comprender a la infancia: "el carácter de dulzura y firmeza, paciencia y celo, bondad y una especie de dignidad (...) exactitud y finura, flexibilidad y método" (Condorcet 1992, pp. 63,98-9, 95-105). Todas las características que la mujer ha ido aprendiendo en calidad de educadora en el hogar la convierten, en su opinión, en candidata idónea para desempeñar el oficio de maestra. Ahora bien, para Condorcet no existen comportamientos, ni dotes que sean innatos en la mujer, pues ahora estas cualidades se consideran un producto social que emana de su experiencia maternal. De esta manera, la naturaleza de las cualidades femeninas, que defiende Condorcet, le coloca en una línea de argumentación que representa el polo opuesto con respecto a las posturas mantenidas por 
Rousseau y Kant en su defensa de las madres educadoras (en tanto que el primero las define como sociales y los segundos como naturales). Sin embargo, existe una similitud entre ellos: ya sea como madres, como en el caso de Rousseau o Kant, o como maestras públicas, como en el caso de Condorcet, todos parecen apoyar que las maestras sean mujeres. Tal acuerdo constituye uno de los principales argumentos en favor de la feminización de la enseñanza primaria.

Los krausistas, por su parte, supieron aprovechar esa puerta que Kant había dejado mal cerrada, pues al acentuar la importancia de los comportamientos femeninos, no sólo a través de la familia, tal como Kant había señalado, sino ahora también por medio de la escuela, el papel jugado por la mujer desde el ámbito privado y público resultaba aún más decisivo para alcanzar la ansiada regeneración social y moral.

Así, y ante la evidencia de que la mujer pasaba más tiempo que el hombre junto a esa infancia, embrión de las generaciones venideras, a la que por experiencia conocía mejor, consideraron que tal función, la maternidad, constituía en sí misma un argumento de peso para permitirle el acceso racional a la cultural y la religión. La influencia positiva y complementaria de la mujer, señalada por Kant, en el hogar, será el punto de partida que utilizarán los institucionistas para proceder a la creación de un nuevo modelo de maestra, más preparada, más "conciencia"de su función de riego para el cultivo del grano infantil. El concepto de "madre concienciada", acuñado por Caroline Steedman, es a mi entender el que mejor refleja el significado de este nuevo modelo de maestra, ${ }^{20}$ que está destinada a compensar las deficiencias sociales y culturales de la infancia.

El cambio hacia el tercer modelo de maestra se produce en paralelo con la implantación de la metodología de Fröebel, que dio al traste con el método memorístico y autoritario propuesto por Montesino, y consiguió crear una mentalidad favorable a la inclusión de la mujer en el magisterio. ${ }^{21}$

\section{La maestra racional intuitiva en la legislación}

A partir de 1881, con la llegada al poder del partido liberal, la educación nacional y las condiciones personales y materiales del magisterio público iban a gozar de un gran apoyo; lo que favoreció enormemente "la elevación de la mujer en este orden de la vida, en el cual con tan irresistible inferioridad se le ha tratado" (Giner de los Rios 1927, p. 36). Efectivamente, las medidas tomadas por Albareda, que procedió a la modernización de los estudios 
de maestra y los cambios introducidos por su gabinete de Gobierno, propiciaron el asentamiento del modelo de maestra racional intuitiva.

El 8 de junio de ese mismo año aparece una disposición que modifica la normativa vigente desde la Ley Moyano. En opinión del legislador, era conveniente adoptar las medidas necesarias para poder aumentar en los próximos presupuestos del estado las sumas destinadas para las escuelas normales; únicos centros públicos encargados hasta ese momento de la instrucción de la mujer. Lo que se estaban pidiendo eran créditos para poder crear el título de maestra en el grado de Normal (que al no ser contemplado por Moyano le impedía ingresar en el cuerpo del profesorado de las Escuelas Normales femeninas y, por tanto, regentar las cátedras de las escuelas). De nuevo, la maestra, con este nuevo título volvía a derrocar una barrera: a partir de entonces podría impartir clases en las Escuelas Normales de Maestras, cuya plantilla de profesorado estaba constituida hasta el momento sólo por hombres. Pero, curiosamente, aunque el título de Normal para los estudios femeninos se había creado en 1882, tres años más tarde, en 1885, sólo figura una profesora impartiendo docencia en escuelas normales (frente a los 367 profesores que ejercían en el sector público, y los 71 que figuraban en el privado); hecho que muestra que el medio social no era aún favorable a la incorporación de la mujer en los niveles superiores. ${ }^{22}$

En 1881 el Gobierno estableció, por primera vez, un plan de estudios específico, con carácter general y uniforme, para todos los establecimientos de España; reguló el acceso a la plaza de Directora mediante el sistema de oposición, siguiendo un programa que establece en esa misma fecha - que, a tenor de los testimonios legados, puso de manifiesto el escaso nivel cultural que presentaban las maestras de la época (Arenal 1895, p.243); fijó medidas para las maestras que, procedentes de estudios privados, la mayor parte de Escuelas Normales de provincias, se sujetarán a las mismas normas y pruebas de actitudes para obtener el título; ${ }^{23}$ amplió a dos cursos - Moyano ordenaba sólo uno - los estudios de maestras aspirantes al título elemental; $y$, a tres, los de superior - que hasta entonces se venían realizando en dos años; y concedió una importancia sin precedentes a las prácticas de las asignaturas del magisterio femenino (es importante recordar que hasta entonces la asignatura de Pedagogía se cursaba tan sólo en la Escuela de Institutrices, pues ni el reglamento de exámenes de 1850 pedía conocimiento alguno de los métodos de enseñanza a ninguna de las dos categorías de maestras elemental y superior -, ni tampoco el reglamento de exámenes de reválida para maestros y maestras de 1864 exigía prácticas en las escuelas modelos a las aspirantes al título de maestras). 
Ahora, la pedagogía de Fröebel comenzaba a penetrar en los estudios oficiales. El conde de Toreno emprendió una importante reforma, y el 15 de marzo de 1876 creaba una cátedra especial, que unía a la Escuela Normal Central de Madrid, para la enseñanza de párvulos por el procedimiento de Fröebel (la edad de ingreso era de tres a ocho años). Las maestras y los maestros, con título elemental o superior, que quisieran obtener el título en la especialidad de párvulos, debían en adelante asistir a las lecciones a cargo de la persona que obtuviese la cátedra. La Dirección General de Instrucción Pública convocaba un concurso para proveer la plaza, que sería ganada por Pedro de Alcántara. El 17 de junio de ese mismo año aparece otra R.O. que exige que las materias reguladas en 1877 (fecha en la cual el Gobierno uniformó el programa de estudios de todas las escuelas normales de maestra establecidas en provincias) ${ }^{24}$ se estudiaran durante el mismo número de años en todas las Escuelas Normales de Maestra. Los efectos de esta reforma iban a resultar altamente positivos para el magisterio femenino en España. Un R.D. de 17 de marzo de 1882 reservaba exclusivamente a la mujer la Dirección de las Escuelas de Párvulos. Los institucionistas habían conseguido ganar la batalla: "Cuando reflexionamos sobre la organización de nuestras escuelas de párvulos, apenas se comprende, a primera vista, cómo su fundador no se atreviese a entregarlas a maestras" (Giner de los Rios 1927, p.36-8). El artículo 15 establecía la organización que se seguiría, a partir del próximo curso, en la Escuela Normal Central de Maestras. La profesora debía aprobar un curso especial para obtener el título de párvulos, que daría derecho a aspirar a las plazas de maestra de primera y auxiliar de las escuelas de párvulos. Por el artículo 10 se crea el Patronato General de Escuelas de Párvulos, que tenía entre sus cometidos el de promover y procurar la creación de escuelas, así como mejorar y perfeccionar las ya existentes. El congreso celebrado en 1882 suscribe la decisión tomada por el Gobierno.

La reforma de 1882 venía a resolver, como indica Cossío, la necesidad de crear un profesorado femenino de acuerdo a las exigencias modernas. ${ }^{25}$ La R.O. de 3 de febrero de 1853 (primera disposición que se dictó para organizar la provisión de escuelas de párvulos, en las que se seguía fielmente la organización escolar que correspondía al modelo de maestra maternal) fue pronto sustituida por otra R.O. de 27 de agosto de 1882, aprobada en el Reglamento de la Escuela Normal de Maestras, que exigía la aplicación, en todas las asignaturas, del método intuitivo: "Las asignaturas (...) versarán (...) no solamente sobre su contenido doctrinal, sino acerca de la manera de enseñarlas (...). A la exposición de las asignaturas debe acompañar el 
manejo y empleo de los medios de intuición (...). La enseñanza se dará con arreglo a (...) los procedimientos intuitivos". ${ }^{26}$ Parece que la maestra racional intuitiva ha comenzado a tomar cuerpo en la esfera oficial.

El 27 de Agosto de 1882 se reorganiza la Escuela Normal Central de Maestras de Madrid (Colmenar Orzaes 1988); la profesionalidad que inspira la directora - recuérdese que a partir de 1881 ingresa mediante oposición - es motivo suficiente para cesar a la Junta de Damas de Honor y de Mérito de sus atribuciones. En adelante, la Junta de Profesores, dirigida por la directora, será la encargada de tratar todo lo relativo a la dinámica del centro y actuará como órgano consultivo de la Dirección General de Instrucción Primaria. Se acaba con ello la dependencia exterior del centro. La Escuela Normal Central de Maestras comienza a tener un sistema de organización propio, con el que venía funcionando la Normal Central de Maestros. Ahora, la directora, que es la supervisora principal, tiene a su cargo la asignatura de labores ${ }^{27}$ (lo que muestra el prestigio de esta materia), y entre sus funciones figura la de entenderse personalmente con las familias de las alumnas e informar y aconsejar a los padres sobre la conducta de sus hijas. La exigencia de cualificación se extiende a las alumnas aspirantes al ingreso en la Normal, que en adelante deberán pasar un examen de ingreso.

Los exámenes se suprimieron, y fueron sustituidos por una calificación de la Junta de profesores, que vigilaba de cerca el trabajo y aprovechamiento de las alumnas durante el curso. En cuanto al ingreso de las alumnas al magisterio, se consideró más acertado optar por el sistema cíclico de contratos, que eran renovados durante cinco años, cesando igualmente el acceso por oposición.

\section{Consideraciones finales}

Las fechas que he utilizado deben entenderse a modo orientativo. Quizá hubiera sido más acertado hablar de períodos. Por ejemplo, en nuestros días el modelo de maestra maternal sería el equivalente al de la maestra al frente de las guarderías privadas, que en la mayoría de las ocasiones no tiene titulación (aunque es de esperar que la nueva especialidad en Educación Infantil modifique esta situación). En Alemania, por ejemplo, el modelo de maestra maternal y el racional intuitivo se llegaron a producir en un mismo momento. Es decir, que estos modelos se han solapado unos con unos y, o bien han llegado a aparecer unidos, o no han terminado de desaparecer con el paso del tiempo. 


\section{Notas}

1. Véase mi tesis doctoral: "Las transformaciones sociales de la profesión de maestra. 1772-1882". 1996, y mi libro Las primeras maestras, 1998.

2. Katz, M., The irony of early school reform, New York, Harvard University Press, 1968, y "The origins of popular educations: A reassessment", en History of Education Quarterly, 1976, pp. 372-384; Green, A., Education and State fornmation. The Rise of education systems in England, France and the USA, Londres, MacMillan, 1990; Aldrich, R., School and society in Victorian Britain, Londres, The College of Preceptors, 1995 y Education for the Nation, Londres, Cassell, 1996; Murphy, J., Church, State an schools in Britain, 1880-1970, Londres, Routledge and Kegan Paul, 1970; Tomlinson, J., The control of education, Londres, Cassell, 1993; Vaizay, J., Education. The State of the debate in America, Britain and Canada, Londres, Duckworth, 1976.

3. Bowles, S. y Gintis, H., Democracy and capitalism: Property, community and the contradictions of modern social thought, Nueva York, Basic Books, 1976; Fernández Enguita, M., "Naturaleza, Sociedad y Educación en Rousseau", en Revista Témpora. Pasado y presente de la educación", 11-12, 1988; Varela, J. y Alvarez Uria, F., Arqueología de la escuela, Madrid, La Piqueta, 1991; Katz, M., The Irony..., opus cit.

4. Las referencias a las obras de Rousseau, Kant y Condorcet para justificar los modelos de maestra que aparecen en España, es un recurso personal de la autora. El lector no debe, por ello, suponer que las obras de estos autores fueran conocidas por los reformadores, moralistas o políticos en España. Aunque es probable que algunos de ellos leyeran a estos autores, no hay ninguna investigación que pueda atestiguar tal afirmación.

5. Hans Van Crombrugge (1995, pp. 445-480) muestra en qué medida el papel social que se le asignó a la mujer estuvo fuertemente condicionado por las nuevas estructuras culturales de la familia burguesa.

6. El ingreso masivo de la mujer en los primeros niveles de la educación a lo largo del siglo XIX se vio favorecido por la justificación de toda una gama de características femeninas. Véanse: Jones, J., "Women Who Where More than Men: Sex and Status in Freedmen's Teaching", en History of education quarterly, 19, 1, 1979, pp. 47-59; Acker, S., "Carry on Caring: The Work of Women Teachers", en British Journal of Sociology of Education, 16, 1995, pp. 21-36; Steedeman, C., "The Mother Made Conscious..., opus cit.; Florin, C., "Who Should Sit in the Teacher's Chair?", en Seppo, S., The Social role and evolution of the teaching profession in historical context, Finland, University of Joensuu, 1988, p. 117; Strober, M. y Tyack, D., "Why Do Women Teach and Men Manage? A Report on Research on Schools", Journal of Women in Culture and Society, Chicago, The University of Chicago Press, 5, 3, 1980, p. 495, y "Jobs and Gender: A History of Structuring of Educational Employment by Sex", en Patricia M. Schmuck et. al. (orgs.), Educational Policy and Management. Sex Differentials, Nueva York, 1981; Apple, M., Teachers and text. A political economy of class and gender relations in Education, Londres, Routledge and Kegan Paul, 1986), Nash, C., "Educating New Mothers: Women and Enlightenment in Rusia", en History of Education Quarterly, 
21, 1981, pp. 301-331; Walzer, J., "Under the Shadow of Maternity: American women's responses to death and debility fears in nineteenth-century childbirth", en Feminist Studies, 12, 1, 1986, pp. 129-154.

7. Elshtain, J.B., Public man, private women: Women in social and political thought, Oxford, Robertson, 1981; Landes, R., The Culture and Politics of work, Londres, Open University Press, 1988; Thomas, P., "Jean-Jacques Rousseau, Sexist?, en Feminist Studies, 17, 2, 1991, pp. 195-217.

8. Resulta interesante la crítica de Roland Martin , J., "Sophie y Emile: Estudio de um caso de prejuicio sexista en la historia del pensamiento educativo", en Educación y Sociedad, 1, 1993, pp. 127-145. En opinión del autor, la educación de Sophie no es el resultado de un proceso natural, sino productivo.

9. Gibert, F. (Capellán titular y maestro de capilla de las señoras descalzas reales), La esperanza feliz de España cumplida en la venida del señor Rey D. Fernando VII. Cantata a cuatro voces (Madrid 1815).

10. El pasante, ayudante de un maestro debía someterse a unas pruebas, o incluso un examen, donde tenía que demostrar sus conocimientos, su moral y sus costumbres

11. El posterior aumento de control y dirección administrativo que se produce como consecuencia de la exigencia de cualificación en la enseñanza, la convirtió en un trabajo que precisaba más tiempo de permanencia y mayores niveles de cualificación; esta situación se produjo en España desde la promulgación de la Ley Moyano en 1857; situación que causó el paulatino abandonado de los hombres de las áreas urbanas, que se fueron a las ciudades a ocupar nuevas profesiones en el comercio y las fábricas. Véase Strober, Myra y Tyack, David, "Why do...", opus cit., pp. 49899. Evans Gareth muestra el número de mujeres y hombres dedicados a la enseñanza en Gales desde 1860 1869. A medida que la enseñanza comenzó a ser menos atractiva para el varón, pues se le fueron abriendo nuevas posibilidades de trabajo, comenzó a ser ocupada por mujeres, "Gender stereotyping and the training of female elementary school teacher: The experience of Victorian Wales, History of Education, 21, 2, 1992 , p. 193.

12. MacCann, P. y Young, F., Samuel Wilderspin and the Infant school movement, Londres, Croom Helm, 1982; Silver, H., The concept of popular education: A study of ideas and social movement in the early nineteenth century, Londres, Maggibbon and Kee, 1965; Raymont, T., A history of the education of young children, Londres, Logmans, Green and Co., 1937; Rusk, R., Infant school education, Londres, 1933; Birchenough, C., History of elementary education in england and wales: From 1800 to the present day, Londres, Universiry Tutorial Press, 1933 ; Higginson, J.H., "The Dame School in England", en Vàg, Otto, (ed.), Conference Papers for the 4th Session of the International Conference for the History of Education, Budapest, 7-10 de septiembre, Eötvös Loránd Tudományegyetem, 1982, pp. 141-155; Singleton, W.A., Development of nursery and elementary schools in Great Britain, Liverpool, 1945; Kate, S., Pestalozzi. The man and his work, Londres, Routledge and Kegan Paul, 1960, pp. 167-181. 
La primera escuela de párvulos, que se abrió en España el 10 de octubre de 1838 con el nombre de "Virio" y el carácter de escuela-modelo, servió de ejemplo a las que posteriormente fueran apareciendo. Esta primera escuela de párvulos siguió fielmente el modelo de maestra maternal propuesto por Montesino. Don José Bonilla, discípulo de Montesino, ayudado por su esposa en tareas menores, se hizo cargo de ella. Más adelante, en 1850, convertida en la primera Escuela Normal Central, pasaría a depender del Estado, que confió al Señor Bonilla el cargo de Director de la misma.

13. Político progresista y Diputado en las Cortes de Cádiz de 1821, emigró a Inglaterra tras la vuelta de Fernando VII a España en 1823. En 1833 vuelve a España, donde participa activamente en las reformas educativas que se suceden desde entonces. Al frente de su cargo de Director General de Enseñanza Primaria y Consejero Nacional de Instrucción Pública se interesó por dos campos de cultivo, fértiles, pero poco atendidos: el asunto de la educación de la mujer y la formación de la infancia

14. Catarsi, E., (ed.), Twentieth century pre-schools education. Times, ideas and portraits, Milán, Centro Studi "Bruno Ciari", 1985; Cosnier, C., Marie Pape-Carpantier de l'école maternelle à l'école des filles, París, L'Harmattan, 1993; Dajez, F., Les origines de I'école maternelle, París, PUF. 1994; Luc, J. N., La petite enfance a l'école, XIX siècles, París, Institute National de Recherche Pédagogique, 1982; Vàg, O. (ed.), Conference, opus cit., y Historie Infantiae. International Annual for the history of early childhood education, 1, Budapest, opus cit. ; Erler, L. y Erning, G., Conference Papers for the 1st Meeting of International Standing Working Group for the History of Early Childhood Education, Bamberg, 29-30 de agosto, 1984.

15. Quisiera subrayar la influencia de Kant sobre este planteamiento: "...el carácter es el principio de vigencia universal en el hombre (...) el modo de hacer de su voluntad. Un hombre que no tiene ningún principio estable de sus acciones no tiene carácter (...) las mujeres (...) tienen poco carácter" en Pedagogía, opus cit., pág. 106.

16. Actas del Congreso Nacional Pedagógico, Madrid. Librería de D. Gregorio Hernando, impresor y librero de la Real Academia Española, 1882, p. 466.

17. Nuevo manual de las clases maternales. Llamadas salas de asilo, para el uso de las hijas de la Caridad de San Vicente de Paul, Madrid, Imprenta de Tejado, 1858.

18. Resulta curioso que a ninguna de las dos categorías de maestra se les exija conocimiento de los métodos de enseñanza; de hecho hasta 1882, año en que tuvo lugar la reorganización de la Escuela Normal de Maestras, su formación pedagógica quedó reducida a principios de Educación y Métodos de enseñanza; a partir de ese año se incluye en el curriculum de las maestras la asignatura de Pedagogía.

19. Los inspectores de enseñanza recibieron la apertura de la escuela con gran entusiasmo (Pirala 1858, p. 369).

20. teedman, C., Childhood, culture and class in Britain, 1860-1931, Londres, Virago Press, 1990; "The Mother Made Conscious: The Development of a Primary Pedagogy", opus cit., pp. 149-163 , y "Prisonhouses", en Lawn, M. y Grace, G., (eds.), Teachers: 
The Culture and Politics Work", Lewes, Falmer Press, 1987, pp. 117-129

21. Taylor muestra en qué medida los modelos de maestra que se fueron sucediendo en Alemania a lo largo del siglo XIX - que, por cierto, se corresponden con el modelo de maestra maternal y racional-intuitiva -, surgieron al ritmo de exigencias metodológicas. El aula reproducía el modelo de una estructura sociofamiliar directamente relacionada con intereses políticos y sociales. El método tradicional exigía la presencia de una maestra, con muy poca preparación previa, que ayudaba al hombre a cuidar maternalmente de los niños, en Jardines de niños. Jardines de Dios: Kindergartens y guarderías en Alemania en el siglo XIX, Revista de Educación, № 289, 1986.

22. Estadística de Primera Enseñanza (1871-80), Madrid, M.E.C., parte II, nos 25 y 26.

23. R.O. de 25 de Junio de 1881, en Colección Legislativa de España, CXXVI, Madrid, 1881 , pp. 1.282-3.

24. R.O. de 14 de Marzo de 1877 autorizando a la Diputación Provincial de Toledo para la creación de unas reglas a las que han de sujetarse las escuelas. Diccionario de la Administración VI, 1876-7, p. 494.

25. Las maestras de 1880 no aprendían, ni, por tanto, enseñaban, y la cultura general femenina, en las clases media y alta apenas podía representarse matemáticamente por algunas décimas sobre cero (leer, escribir, recitar el catecismo y... sumar, no muy expeditivamente), y las de las clases bajas estaban tan a cero, que casi no existía (Saiz 1929, p.57).

26. Artículos 11, 12 y 31 de la R.O. de 27 de Agosto de 1882, en Colección Legislativa de Primera Enseñanza, 1877-1883.

27. En España las maestras tuvieron que someterse al examen de labores hasta 1967.

Recebido para publicação em Outubro e 2000.

\section{The spanish teacher from the traditional to modernity}

The objective of this paper is to explain the origin and development of the incorporation of the teacher in the state school in Spain from 1783 to 1882. I the time line that crosses this historical period, from the Illustration and the Restoration, it's to believe to find theoretical, educational, social, political, religious and economicals foundations enough to bring teachers that allow to show their faces in the state school incorporation. These Periods shows, on the other hand, a kind of prejudice - as being negative, through exclusion - illiterate teacher - as being positive, through inclusion - maternal and rational intuitive teacher. The study is framed within an investigation made in Spain, defended as a doctoral thesis in 1996 entitled "The social changes in the teacher profession in Spain", 1772-1882 and latter revised en the Education Institute of London University. The conclusion from this 
investigation has been recently published with the title: "The first teachers. The origin of the womanly teaching process $i$ Spain.

\section{Referências Bibliográficas}

APPLE, M. Teacher and text. A political economy of class and gender relations in education. Londres: Routledge and Kegan Paul, 1986.

ARENAL, C. "Estado actual de la mujer española", en Boletín de la Institución Libre de Enseñanza, XIX, 1895.

COLMENAR ORZAES, C. "Historia de la Escuela Normal Central de Maestras de Madrid, 1858-1914", Tesis doctoral, Madrid, Universidad Complutense, 1988.

COMBRUGGE , H.V. "Rousseau on family and education", Paedagogica Historica. International Journal of History of Education 2, 1995.

CONDORCET, M. de. "Sobre la admisión de las mujeres al derecho de ciudadanía", In: PULEO, A. Condorcet, De Gouges. De Lambert y otros. La llustración olvidada. La polémica de los sexos en el siglo XVIII, Madrid: Anthropos, 1993.

. Escritos pedagógicos, Madrid: Espasa Calpe, 1992.

GAGO, Sonsoles S.R. Las primeras maestras. Barcelona: Editora Ariel, 1998.

."Las transformaciones sociales de la profeción de maestra 17721882". Tesis doctoral, Departamento de Sociologia de la Universidad de Salamanca, 1996.

GIL DE ZÁRATE, A. De la Instrucción Pública en España, I. Madrid: Imprenta de sordomudos, 1855.

GINER DE LOS RIOS, F. Obras Completas, XVII, Madrid: Imprenta de Julio Cosano, 1927.

KANT, I. Antropología en sentido pragmático. Madrid: Alianza Editorial, 1991. . Observaciones acerca del sentimiento de lo bello y lo sublime. Madrid: Alianza Editorial, 1990.

. Pedagogía. Madrid: Akal.

MARTíNEZ ALCUBILLA, M. Códigos antiguos de España. Madrid: Ed. Arco de Santa María, 1880. 
MOLINA PETIT, C. "llustración y feminismo. Elementos para una dialéctica feminista de la llustración". In: AMOROS, C. Feminismo e llustración, 1883-1992. Madrid: Instituto de investigaciones femininstas, 1992.

MONTESINO, P. Manual para los maestros de escuelas de párvulos. Bilbao, 1840.

OSSENBACH, G. "German influence in Latin American Pre-school Education $\left(19^{\text {th }}\right.$ Century)". In: VÀG, Otto. Conference Papers for the $4^{\text {th }}$ Session of International Standing Conference for the History of Education, I. Budapest, 7-10 de septiembre, Eötvös Loránd Tudományegyetem, 1982.

PESET, J.L. y PESET, M. La universidad española. S. XVIII y XIX, Madrid: Taurus, 1974

PIRALA, Antonio. El profesorado. Revista de instrucción pública. 1857-1885, Madrid: Establecimiento tipográfico de D.F.. de P. Mellado, 1858.

QUINTANA, M. J. Obras completas, Madrid: Biblioteca de Autores Españoles, 1946.

ROLAND MARTIN, J. "Sophie y Emile: Estudio de un caso de prejuicio sexista en la historia del pensamiento educativo". Educación y Sociedad 1, 1993.

ROUSSEAU, J. J. Emile o de la Educación. Barcelona: Fontanella, 1973.

RUIZ, J. Política escolar de España en el siglo XIX. 1808-1833. Madrid, CSIC, 1970.

SAIZ, C. La revolución del 68 y la cultura femenina. (Apuntes al natural). Madrid: Librería general de Victoriano Suárez, 1929.

SCANLON, G. "Revolución burguesa e instrucción femenina", Nuevas perspectivas sobre la mujer. Seminario de estudios de la mujer de la Universidad Autónoma de Madrid, 1982.

SUBIRATS, M. "El modelo de educación femenina en la etapa de formación de la escuela moderna". In: V.V.A.A., Sociedad, cultura y educación. Homenaje a Carlos Lerena, Madrid, Centro de Investigaciones Sociológicas, 1990. 